\title{
The Impact of Creativity and Innovation on Entrepreneurship Development: Evidence from Nigeria
}

\section{Nwokebuife Onyinyechi Juliana*, Han Jun Hui, Mintah Clement, Ejiofor Nnaemeka Solomon, Ofori Kwame Elvis}

School of Economics and Management, Taiyuan University of Technology, Taiyuan, China

Email: `julianagift77@gmail.com, kjcyyk@126.com, yawmintahclement@gmail.com, ejioforsolomon.com@gmail.com, oforikwamee@gmail.com

How to cite this paper: Juliana, N. O., Hui, H. J., Clement, M., Solomon, E. N., \& Elvis, O. K. (2021). The Impact of Creativity and Innovation on Entrepreneurship Development: Evidence from Nigeria. Open Journal of Business and Management, 9, 1743-1770.

https://doi.org/10.4236/ojbm.2021.94095

Received: June 5, 2021

Accepted: July 12, 2021

Published: July 15, 2021

Copyright $\odot 2021$ by author(s) and Scientific Research Publishing Inc. This work is licensed under the Creative Commons Attribution International License (CC BY 4.0).

http://creativecommons.org/licenses/by/4.0/

\begin{abstract}
This paper seeks to investigate the relationship between creativity and innovation on entrepreneurship development. Before doing so, we marry the insights of several pieces of works of literature on creativity, innovation, and entrepreneurship stemming from Joseph Schumpeter's perspectives, theory, and research on innovation and entrepreneurship development. A survey design was adopted for the study. A valid sample of 257 impacted the study using Yemane sample size determination formulae. The research employed the Ordinary Least Square method and ANOVA Test for data analysis. In this study, we accept hypotheses $\mathrm{H} 2$ and $\mathrm{H} 5$ due to their significant and mutual relationship on the measured variable whereas $\mathrm{H} 1, \mathrm{H} 3$, and $\mathrm{H} 4$ were not accepted owing to their insignificant impact on the independent variable (entrepreneurship development). The most significant variables in this research are technological advancement and strategy. The findings of this research are quite different from the influential factors (Ali Al Qudah 2018). The two measured significant variables can then be considered as major factors or requirements for innovation and the success of a country's entrepreneurship development. Having established this fact is a call on policy support and framework-specific not only for Nigeria but to any other country which is striving to achieve economic success. Interestingly, the matrix analysis established a strong relationship between creative thinking and innovative ability, as well as technological advancement although was negatively estimated on entrepreneurship development. This indicates that technological advancement is support for creativity and innovation. However, its direct effect on entrepreneurship development was not significantly estimated. This can further be investigated to ascertain reality. Therefore, this is a call on policy support and
\end{abstract}


framework not only for Nigeria but to any other country which is striving to achieve economic success.

\section{Keywords}

Creativity and Innovation, Entrepreneurship Development, Nigeria

\section{Introduction}

Creativity and innovation are topics of discussion that are particularly relevant in research work which are seen as important factors in the creation of competitive advantage. Innovation has almost become a requirement in today's global business environment, regardless of a company's market reach. Drawing on more than a decade of OECD (Box, 2009) research, this report provides a general overview of what we know about excellent policy approaches for innovation. It also discusses recent developments in innovation processes and patterns, outlines rising degrees of internationalization, and compiles early thought on the role of innovation in addressing global environmental concerns. This is due to the new reality that every company's rivalry reaches well beyond its local market. Entrepreneurs and companies that realize this early on bring innovation to the market. Innovation is the secret to entrepreneurship and the productive development of the competitive edge. The foundation for innovation is creativity. However, while creativity is needed for innovation, it is not always sufficient. The implantation of creative inspiration is innovation. For some industries, the capacity to generate continuous innovation has not only become a key success factor, but also a requirement for survival. Importance of Creativity and innovation aid in the development of new ways to improve an existing product or service to maximize profits. This also encourages entrepreneurs to think outside the box and look for answers that aren't standard. Through this opportunity, a new, intriguing, potentially lucrative, yet adaptable idea emerges. Moreover, it helps in the sustainability and long-run performance of all kinds of companies (Baykal, 2018).

The economic and social consequences of today's global challenges affect societies and the entire world. Many governmental and philanthropic efforts are failing to achieve the social change that communities around the world demand and key social sector institutions are frequently considered inefficient in resolving social concerns (Fields, 2016). Many entrepreneurs regard creativity and innovation as critical elements, there continues to be a lack of understanding of the factors that affect these elements, as well as the management of relevant processes (Finkle, 2013). Recently, an economic transition has been established. The economy is shifting away from knowledge-based activities and toward activities that require creativity, innovation, entrepreneurship, and imagination (Oke et al., 2009; Fillis and Rentschler, 2010). 
More business opportunities have arisen as a result of increased globalization and technological effects, but the marketplace has also become more crowded, resulting in increased competition (Jain, 2019; Edralin et al., 2019). Creativity also allows the entrepreneur to act on these opportunities in ways that will give the company a competitive advantage. It can serve as a foundation for creativity and business development, as well as have a positive effect on society as a whole (Ballor and Claar, 2019). Entrepreneurship can be seen in all forms and sizes of businesses, from small local businesses to multinational corporations.

Entrepreneurship, according to Clow (2008), is the process of mobilizing and sacrificing resources (land, capital, and human resources) to use a business opportunity or execute an idea in a way that meets society's needs for products and services, creates employment, and benefits the venture's owner. Both new and established businesses are involved in this process, but the focus is usually on new products or services and new businesses. Therefore, for a country to prosper and enjoy continued economic growth, creativity and innovation have to be injected into the entrepreneurship development agenda has to be pursued.

Creativity and innovation can also be extended to things like coming up with business ideas, such as what to manufacture to satisfy customers, finding investment opportunities, deciding how to capitalize on those opportunities, formulating corporate goals and objectives, and conducting market research in both urban and rural areas. Creating an enterprise, starting real business operations, selling and promoting an organization's products and services, planning and managing human and material capital for the achievement of the enterprise's goals, risk and uncertainty management, creativity, and diversification (Gontur et al., 2016).

Consequently, the case of Nigeria is different. The Majority of Nigerian entrepreneurs today need a practical way of combining the needed resources and opportunities in a variety of ways. Their level of creativity is not as high as that of the Western World. They have failed to engage in adequate preparation, scheduling, staffing, managing, and directing, as well as the opportunity to take a commensurate risk with their capital and other resources in new business projects from which they anticipate significant rewards.

Most small and medium businesses in Nigeria lack prudent management decisions, ideas, originality, and foresight on what to produce when to produce it, and how best to produce it to satisfy their customers and make a profit. These would have been improved if the entire management team adopted sound creativity and innovation practices.

In support of the above, innovation has been defined by (Okpara, 2007) as the addition of something new to an existing product or price that has already been built from the ground up and proven to work fairly well. The study established a positive relationship between creativity, innovation, competitive advantage, and entrepreneurship growth in Nigeria. Therefore creativity can be thought of as the creation of raw material, then the invention process can be thought of as the 
transformation and development of that material into something concrete, such as a process or a product. The relationship between creativity and innovation is neither simple nor straightforward. This problem lies in the fact that this confusion may introduce non-optimal process management of both. This uncertainty causes ambivalence among researchers and practitioners, as well as confusion about the conditions that promote creativity and innovation, as well as the effects of established practices on individuals and the environment in general. Efficiency in these processes is a key competitive advantage in industries that demand constant creativity and innovation from their employees. Continuous innovation of certain companies deemed creative is particularly interesting, given some fundamental paradoxes such as the routine/creativity couple (Fillis, 2010).

According to (Byers, 2017), the generation of innovative and potentially useful ideas can be applied to several strategic areas of the business, such as products, services, processes, and procedures. Ideas are considered innovative if they are distinct from other ideas currently available in the industry, and may also be considered useful if they have the potential for direct or indirect benefit to the business in the short or long term (Barroso-Tanoira, 2017). Given the above means that the tenets of creativity have to do with the production and application of ideas, or simply put the transformation of ideas into a particular organizational element, such as a product or a method.

In outlining the distinction between creativity and innovation, Byers (2017) successfully demonstrated the causality relation between creativity and innovation. Creativity-can be described in a way to generate ideas which, will be utilized in the innovation mechanism as they are selected, assembled, rearranged, and synthesized toward the emergence of output or a novel. Innovation can be defined as radical or gradual, as a product or a process. The degree of radicalization or incrimination is strongly dependent on previously used methods, both in terms of creativity factors and structuring mechanisms, in terms of creativity variables and structuring processes (Roopsing and Nokphromph, 2017).

The above proposition indicates that creativity and innovation are mutually dependent, go hand-in-hand or are intertwine. As a rule, the resulting innovation is associated with either a form of product or process that is new or improved (Antonites and Van Vuuren, 2014). These resources, facilitating factors, transformation mechanisms, tensions, and their results are different in each case. However, we also recognized that the outcomes of the creative process serve as essential tools for the process of innovation.

Consequently, these two concepts are used to accomplish distinct but complementary goals. Creativity is used to produce ideas, which are then structured and concretized as part of the innovation process to become tools for solving technical issues and increasing productivity while conferring an added value to the products (Acs and Audretsch, 2005).

Accordingly, the difficulty here is not about strategic ways of thinking and injecting innovative ideas to secure a competitive advantage within the business 
environment which will then translate into the development of the entrepreneurial sector and eventually boosting economic growth. Since it is evident in literature that lack of corporate innovation is the most basic and logical cause of Nigeria's slow entrepreneurial development (Okpara, 2007) lack of trust, apprehension, and anxiety, as well as the environment and poor management, overreliance on self-ability, lack of preparation and organizing in terms of technical and innovativeness and creativity, are all factors that have contributed to Nigeria's slow rate of innovation and creativity. This propels the search into the topic to investigate how creativity and innovation could be used to help Nigerian entrepreneurs develop their businesses.

\subsection{Statement of Problem}

The business environment is changing and this requires innovative, strategic, and entrepreneurial minds to help bridge the business gap. Through innovativeness and creative thinking ability. This will help meet the needs, tastes, and preferences of the market environment. Therefore, ridding the failure of most businesses in Nigeria as a result of poor market analysis, lack of creative thinking, an over-concentration on one or two markets for finished goods, lack of succession plan, inexperience, lack of proper book-keeping, a lack of proper records or no records at all, insufficient resources, lack of technology, poor management support and so on are impediments to entrepreneurship development in Nigeria. These are problems that require many investigations and testing to ascertain or establish a fact as stated in literature (Onugu, 2005).

Nigerians have been unable to contribute to the country's entrepreneurship development despite government efforts to promote entrepreneurship in Nigeria (Onuselogu and Zita, 2018), entrepreneurship growth has been sluggish, and failure and even death have been common. This scenario contrasts sharply with the unprecedented entrepreneurial growth of Europe, Asia, and the United States. Further literature by (Oke et al., 2009) suggested that a lack of corporate innovation is the most fundamental and rational cause of Nigeria's slow entrepreneurial development

\subsection{Research Purpose and Research Hypotheses}

The study aimed at the following specific objectives. Today's organizations are ready to invest in artistic specialists to solve entrepreneurial and organizational issues. To bring a better understanding of the research problem, this study investigated new practices-the intentional use of creative interventions in organizations to sustain cohesion and well-being. The empirical research aimed at understanding the impacts of creativity and innovation and entrepreneurship development by testing five (5) variables. The following hypotheses were tested to establish their significance in the study.

$H$ (1): Government policy support on entrepreneurship development (Not significant). 
$H(2)$ : Technological advancement influences entrepreneurship development (Significant).

$H$ (3): Creativity and innovation are means to entrepreneurship development (Not Significant).

H (4): Available resources influence entrepreneurship development (Not significant).

H (5): Strategy influences entrepreneurship development (Significant).

\subsection{Theoretical and Practical Significance}

Having regressed, tested, and established the relationship between the variables in the analysis, we then confirmed how feasible the results are in ascertaining the credibility of the research outcome. Therefore when injecting creativity and innovation into the entrepreneurial sector requires technology and map out strategy as key approaches to entrepreneurship development and success (Nnadi, 2014a). This will help solve the existing problems in the entrepreneurial sector in Nigeria. This will aid economic viability as well as grow, and develop the entrepreneurial sector by aiding businesses and determining their sustainability. Besides, it will help entrepreneurial decision-makers and entrepreneurs determine the positive economic benefits of their creative thinking and innovative ability. The expected result of this dissertation, would stand as a reference point for and will be more beneficial to business owners and managers, and even to educate young entrepreneurs as well as management of the entrepreneurial sector in $\mathrm{Ni}$ geria and across the globe.

\section{Related Theoretical Basis and Literature Review}

\subsection{The Concept of Creativity, Innovation, and Entrepreneurship}

Creativity and Innovation describe as the heart and the soul of enterprise. It entails attempting to carry out tasks in a specific way or to conduct a variety of activities to provide the entrepreneur with a unique mix of value. The benefit of creativity and innovation is that it allows state entrepreneurship to deliberately seek out opportunities to do new things or to do old things in innovative ways. As a result, whatever new paths are dictated by market conditions and consumer desires, creativity and innovation inspire and drive excellent entrepreneurship in guiding organizational operations, delighting customers to the benefit of all stakeholders. In entrepreneurial terms, this becomes a value creation (Korsgaard and Anderson, 2011). The implementation of creative inspiration is described as Innovation.

Hence, a competitive advantage for all businesses to thrive and means of anticipating and satisfying consumer needs, and the method of using technology, are built on innovation. Information gleaned from new connections, experiences gained from journeys to other disciplines or locations, and active and collegial networks all fosters innovation. The philosophy of innovation, described as the use of an idea to produce a new commercial product or service, is the driving 
force behind the development of new demand and, as a result, new wealth, according to Schumpeter (1934). Entrepreneurs bring innovative products to the market, and creativity generates new demand established markets will be disrupted, and new ones will be created, which will be destroyed by even newer products or services.

The results of creativity are about coming up with new ideas, and new technology (Klein, 2008). Creativity is described as the ability to invent or otherwise bring something new into being, whether it's a new approach to a problem, a new method or device, or a new object or form of art. On the other hand, Sart (2013) describes creativity as something unique and useful. Creativity is the act of seeing something that everyone else does but connecting it in ways that no one else has. Creativity is shifting from the familiar to the unfamiliar. According to Weigel et al. (2014), culture harms creativity.

In terms of economics and structure, there are three key characteristics of entrepreneurs. This involves taking risks, innovating, and launching new business ventures for profit. Entrepreneurship is a multidimensional term encompassing multiple dimensions. Due to the Multi-dimensional nature of entrepreneurship, scholars have been forced to think about it in a variety of ways and from various perspectives. It's also worth noting that entrepreneurship has evolved as an ideology over time and that its definition has changed as well. Entrepreneurship, for example, was once used to describe a person's ability to handle massive production projects (Bélanger et al., 2016). This way, the focus is on the individual's ability to handle projects with limited resources, and his willingness to take the risk in other to make a profit.

As a result, a typical entrepreneur in the middle ages was someone in charge of overseeing large architectural projects such as the fortification of cathedrals, abbeys, and public buildings. When people began to associate entrepreneurship with risks in the 17th century, their views change. During this time, an entrepreneur was described as a person who was hired by the government to provide a specific product or perform a service, and who received a profit or loss as a result of the contract. According to Aydin (2015), an entrepreneur is a risk-taker who can buy goods at a certain price and sell them at a different price. Farmers, merchants, craftsmen, and other sole proprietor's exemplified entrepreneurs during this era, according to this view.

Entrepreneurs were viewed as venture capitalists later in the 18th century. This perception shifted somewhat in the 19th and 20th centuries when entrepreneurship was perceived mostly through the lens of economics and was not differentiated from management. As a result, an entrepreneur is described as a person who operates and manages a business for personal benefit and who pays prices for materials used by the business, as well as for the use of property, resources, and personal services provided. This individual accepts the risk of making a profit or losing money due to uncontrollable and unexpected circumstances (Gholami and Karimi, 2014). The element of innovation was introduced 
to the description of entrepreneurship in the twentieth and twenty-first centuries.

Today, entrepreneurs are viewed as individuals with the potential to revolutionize production patterns by using innovation (Antonites and Van Vuuren, 2014). An entrepreneur is a businessperson who starts (builds), develops, and manages a business enterprise to make a profit or benefit from it. Similarly, Fedorowicz et al. (2008) defines entrepreneurship as a person who uses his or her attributes, such as risk-taking, creativity, innovation, and the ability to organize and schedule activities, to put ideas into action to achieve a specific goal.

\subsubsection{Compelling Factors of Entrepreneurship Development and Mitigating of Challenges}

In the entrepreneurial sector, there are a good number of compelling factors that need to be taken into accounts in other to bring innovations into already existing processes and eventually helps in solving entrepreneurial issues or problems. Entrepreneurship is neither a feature of the economy nor a collection of personality characteristics. Entrepreneurship, on the other hand, is a pattern of managerial action and a management strategy that entails seeking opportunities without regarding the risk that is involved or the resources currently under control. The following five essential dimensions of business practice can be used to simplify this definition of entrepreneurship: technology, strategy, resources, culture, and management support. These are the most important aspects of running a company. Several actions influence these dimensions. The argument is that entrepreneurial management is a broad term that covers a wide range of activities on both ends of the spectrum. An entrepreneur is viewed as a promoter who is confident in his ability to capitalize on opportunities regardless of available resources. On the other hand, an entrepreneur is regarded as a trustee who prioritizes the most effective use of available resources.

\subsubsection{Strategies}

Entrepreneurship, according to Acs and Audretsch (2005), entails the formulation of strategic plans. Entrepreneurs are seen as promoters, strategists, and opportunity-oriented people. They are driven by their expectations of existing opportunities to create and execute an idea and to use resources under their influence, rather than by resources available to them. Entrepreneurs are opportunistic, creative, and innovative because they are strategy-oriented. Two major factors are forcing them to adopt new strategies: diminishing opportunity sources and rapid technological change. These individuals are said to show a commitment to opportunity by actively pursuing it rather than passively accepting it. As marketers, entrepreneurs show a willingness to move rapidly in search of an opportunity. They have earned the reputation of gamblers due to their ability to get out and in quickly, and they are also regarded as risk-takers as they establish tactics and learn about the territory in which they work, according to Acs and Audretsch (2005). 


\subsubsection{Resources}

Multi-stage resource commitment is another trait of successful entrepreneurship. Entrepreneurship, according to Ballor and Claar (2019), is about determining the resources required to explore a specific opportunity. In addition, Ballor and Claar (2019) stated that entrepreneurship entails balancing the tension between the amount of capital invested in a business and the potential return. Entrepreneurs often aim to reduce their resource set to optimize the creation of value. Several factors drive the process of contributing capital to the entrepreneurial domain, according to Ballor and Claar (2019). Social needs; a lack of predictable resource needs; personal risk management; international demands; a lack of long-term control; formal planning systems; capital allocation systems; performance compensation; and managerial turnover are some of these causes.

\subsubsection{Technology}

The main motivator and driver of entrepreneurship, as well as the driving force behind society and national economies, is technology. Employment development, economic growth, productivity growth, and economic growth are all said to be fueled by technology-driven entrepreneurship (Edralin et al., 2019). The theory is that technology propels entrepreneurship while also influencing the mindsets, values, and actions of entrepreneurs. Each technological breakthrough, according to Acs and Audretsch (2005), is followed by a slew of new entrepreneurs and start-ups. Furthermore, Acs and Audretsch (2005) stated that the availability and transmission of technology and creative ideas, as well as the existence of infrastructure that supports entrepreneurial efforts, influence entrepreneurial activity.

\subsubsection{Management Support}

The management of every company plays a critical role in the development of entrepreneurs. Corporate entrepreneurship is supported by the supervisory style and support of leaders and managers, according to Phan et al. (2015). Again, Phan et al. (2015) argued that organizations or businesses that do not promote entrepreneurship and struggle to innovate will face inevitable disruption. Moreover, Okpara (2007) noted that one way for companies to prevent creative destruction and remain on a growth path is to promote and cultivate entrepreneurial environments (i.e., fostering entrepreneurship within the firm) to ensure growth, productivity, and sustainability (Onuselogu and Zita, 2018).

Other researchers have backed up the concept that organizational support is a driving force for entrepreneurship (Phan et al., 2015). An organization should encourage entrepreneurship, according to Vétillart (2014), by ensuring that opportunities are available for individuals to introduce innovative ideas, as well as promoting conversations about new ideas, rewarding good ideas, and top management voicing entrepreneurship commitment.

\subsubsection{Culture}

Culture is one of the major factors that affect entrepreneurship, as revealed by 
Institutional Economic Theory. Culture is made up of elements that define a culture and decide how people behave in that society (Amabile, 1988). Culture affects societal entrepreneurial activity by shaping corporate actions of individuals, according to Amabile (1988), social institutions, especially norms and culture, have been described as dimensions of entrepreneurship because of their effect on how individuals perceive the social position of entrepreneurs and how individuals develop the motivation to become entrepreneurs (Amabile, 1988). Entrepreneurial activity is socially adaptive and responsive to a variety of cues from that context.

\subsubsection{Creativity and Innovation in Businesses}

Innovation and creativity are essential skills for success in any form of enterprise. To solve a management challenge, one requires creative insights. Creativity is described as an individual's ability to come up with fresh and original ideas to achieve a purpose. The application of creativity to find a solution to a problem is known as innovation (Neely and Hii, 1998). This simply means that creativity is a means to problem-solving. It is the application of a new approach, new concept, product, or method to increase a system's effectiveness or performance. It encourages imagination by encouraging others to view a problem from a different perspective. It involves dismantling and reorganizing our understanding of a subject to obtain a new viewpoint and new insights. People and method are the two most important elements (Neely and Hii, 1998). It is focused on the process of assisting a person or organization in finding a solution to an issue (Ibbotson, 2008). The resource that responds is people. Creative people use this inventive method to find new ideas and issues, approach problems from new viewpoints, and develop theories about the issue (Neely and Hii, 1998; Roopsing and Nokphromph, 2017). Entrepreneurial spirit keeps businesses afloat and flourishing.

According to Nnadi (2014b), creative and innovative businesses excel by encouraging creative problem solving, driving innovation forward, improving problem-solving, increasing efficiency, and providing a competitive advantage to a company. Innovation benefits business transformation, transition, performance, management, and overall sustainability. It's also a lever for people to be empowered, engaged, and encouraged to make major improvements to structures, cultures, people, goods, and processes. It contributes to improved organizational productivity, scope, and participation, as well as faster business growth and greater value (Nnadi, 2014b).

\subsubsection{The Role of Entrepreneurship Initiatives in Increasing Creativity and Innovation}

The task of creating jobs is enormous. To employ the growing number of youth entering the working-age population in Sub-Saharan Africa and South Asia alone, 28 million jobs will be required per year. This will necessitate a significant rise in both wage and entrepreneurial employment. And, in the long run, increasing 
business productivity and growth is critical for creating more and better jobs (WBG, 2020). Both within the World Bank Group and among our client countries, the importance of a thriving private sector in producing jobs and resolving developmental difficulties is widely acknowledged. For example, countries invest millions of dollars in SME development initiatives, but there are various hurdles in making such investments effective, and policy decisions must be evidence-based to achieve this (WBG, 2020).

Having said this entrepreneurship is the key function to innovate. According to Nnadi (2014b), innovation is a method for entrepreneurs to endow existing resources with greater potential for wealth creation as well as a method for creating new wealth-producing resources. Entrepreneurs should inquire, listen, and go out and look for it because it is perceptual and conceptual. They analyze people and figures to come up with an innovation that satisfies the opportunity. In other places, Schumpeterian considers creativity as a criterion of entrepreneurship, with the desire to do things that have never been done before as one of its distinguishing characteristics. This latest strategy is a unique solution to three different situations. The creative response's first characteristic is that it can never be understood practically. Second, it has an impact on the course of future events and outcomes. Thirdly, it deals with the quality of employees.

Creativity provides a feedback loop in which entrepreneurship promotes innovation and creativity while also encouraging innovation and creativity. Innovation, according to (Acs and Audretsch, 2005), is the process of putting concepts into practice. It entails the development of new supply sources, technologies, and products, as well as the creation and use of new markets and business models. Entrepreneurship, on the other hand, has been described as a term that involves the exploitation and discovery of opportunities, and it is generally regarded as the most effective way to increase innovation and creativity. Indeed, believes that entrepreneurship as a concept is all about creativity and innovation, implying that entrepreneurial initiatives can foster creativity and innovation.

To back up a claim, Ballor and Claar (2019) identified three lines of evidence that support the idea that entrepreneurship initiatives can help with innovation and creativity. Entrepreneurship is described as an innovative and dynamic function of actors, such as small business owners and managers, or department heads, according to the first strand of literature. There is no link between entrepreneurship and creativity in this thread. The second line of research distinguishes between non-innovative companies and those that are innovative. The third and final strand looks at family-owned companies and distinguishes between less creative and more innovative entrepreneurship (Babu, Krishna et al., 2013).

Innovation is the desire for change in an organization. Every dynamic organization is linked to growth, and technological change is the most common form of change in this regard. With new management, the change may be in the field of organizational development. Both of these elements have a significant influ- 
ence on the production process. Every technical advancement must be carefully handled, or it will become redundant and ineffective (unfit) in meeting people's socio-economic needs. The proper management of technological change will contribute to a company's physical expansion and growth. The efforts of entrepreneurs to transform their companies create possibilities for invention and innovation. To put it another way, technical advancement, imagination, and innovation are all interconnected positively. Although most innovations result in technological advancement, not every advancement is an innovation. Buying the new machine, for example, is a technical transition but not an invention. So, what exactly is innovation?

According to Fillis and Rentschler (2010) describe innovation is the introduction or transformation of a new concept into a product, service, or change in organization or process. It is an essential part of corporate strategy and a constant renewal process that involves the entire organization. Giving to Okpara (2007), creativity is the process of turning the best ideas into practice, which begins with a creative concept that leads to a chain of innovative events. It's about providing consumers with a new value. The ability of an entrepreneur to innovate is critical to his or her success; without creativity and innovation, most entrepreneurs will fail. Entrepreneurial innovation may take the form of new financial markets, new goods, new distribution methods, and new management practices. To ensure that successful innovation occurs, the entrepreneur must ensure that his or her research and development unit is well trained, equipped, and capable of conducting creative activities such as basic and applied research.

\subsubsection{Theoretical and Conceptual framework: Creativity and Innovation, and Entrepreneurial Development}

For a better understanding of creativity and innovation and entrepreneurial development, the research draws on the theory and research on innovation and entrepreneurship development. The creation of a perspective is a crucial part of the creative process Creativity follows a semi-formal process. Both intuition and creativity are examples of creativity that can be improved. It may be questioned, given the variety of elements that determine market success whether or not innovation is a key component of entrepreneurship. Pure or unadulterated creativity is not a sufficient factor of entrepreneurship; it must be supplemented with general business knowledge first sense or foresight to ensure innovation's success (Barnard and Herbst, 2018).

The conceptual view from the concept of creativity and innovation, and entrepreneurial development as framework-specific philosophy served as a guide for the research. The rationale is to understand the interactional relationships between the construct items. The conceptual perspective of creativity and innovation was concluded by drawing the link between creativity and innovation for entrepreneurial development and theory and research on entrepreneurship development which has been conceptualized and explained as an approach to solving entrepreneurial problems and sustainable economic development. 
The whole idea of creativity and innovation is to make it a management tool for entrepreneurship development and serving as a crucial driver for economic success, and sustenance of economic regions. The creative thinking and innovative ability of entrepreneurs coupled with government support can serve as grounds and necessary conditions for sustainable development and economic prosperity. Hence, positioning this concept as a strategic approach for solving entrepreneurial challenges and facilitating entrepreneurship development.

More interestingly, in a research conducted by (Becker, Knudsen et al., 2012) on an examination of Schumpeter's concept of innovation in the context of first and second entrepreneurship theory. He also found Joseph Alois Schumpeter's claim that inventions are the only basic challenge in history and that entrepreneurship replaces today's Pareto optimum with tomorrow's different new thing. The words of Joseph Schumpeter entrepreneurship is Innovation has never seemed as appropriate as now when modern capitalism is in a serious crisis and has lost its energy as a result of the recent subprime and euro-debt crises. Therefore, adopted the innovation and entrepreneurship theory and factored it in this research will propel entrepreneurs to be creative and innovative a bit. However, this can happen effectively by injecting and considering necessary factors such as resources, technology, strategy, culture, government/management support. The research engineer's new inventions, problem-solving, risk reduction, competitive advantage, empowerment, and capacity building of most businesses. This will ease business failures and enhance entrepreneurship development across the globe. Hence, adoption of the concept and practice. This is represented below (Figure 1).

\section{Research Content}

This chapter discusses the research methods used in terms of research design,

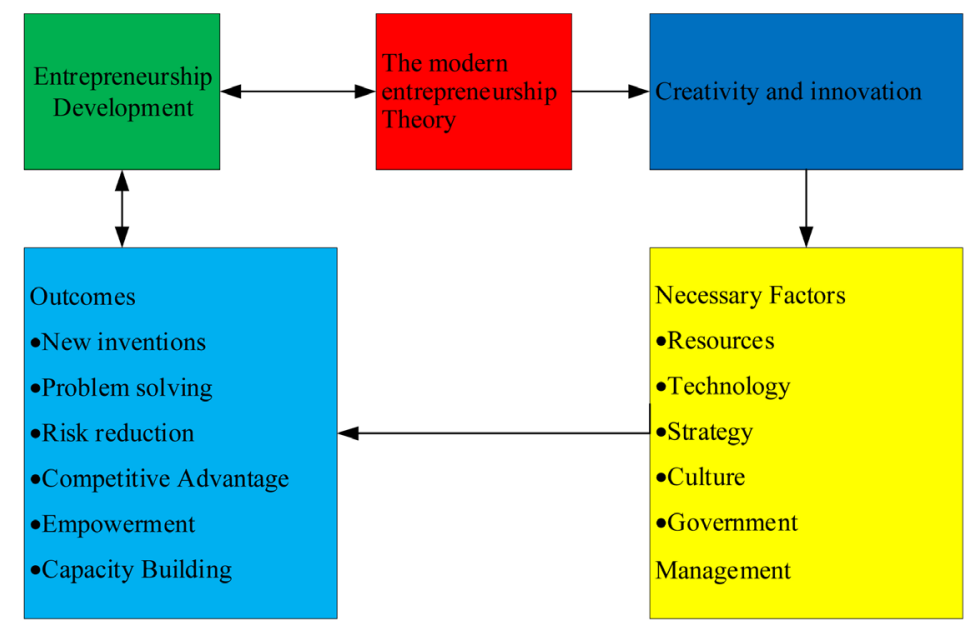

Source: Author's Construct,

2021

Figure 1. Conceptual framework. 
study population, survey and sampling methodology, instrumentation, data collection, interpretation, and statistical analysis. This segment usually responds to the issue of "How" the study was done. Since it is the foundation of the thesis, any research process is reliant on this portion.

\subsection{Area of the Study}

The research was conducted in the Eastern region in Nigeria specifically in Nnewi, the capital city of Anambra state which lies between latitude: $6.0195^{\circ}$ or $6^{\circ} 1^{\prime} 10.3^{\prime \prime}$ North and between longitude: $6.9172^{\circ}$ or $6^{\circ} 55^{\prime} 1.9^{\prime \prime}$ East West and $0^{\circ} 30^{\prime}$ East. The Region has a land area of $4844 \mathrm{~km}^{2}$ (1870 sq-mi). The region has a total of 4,177,821 (NPC, 2006).

\subsection{Technical Route and Research Framework}

The route of inquiry or examination reflected specific goals derived from the research query by identifying the sources from which the data was planned, obtained, and analyzed. This helped in addressing appropriate questions and how to evaluate the related thesis question formulated (Figure 2).

\subsection{Research Design}

A survey research design was adopted for this research work. This method of

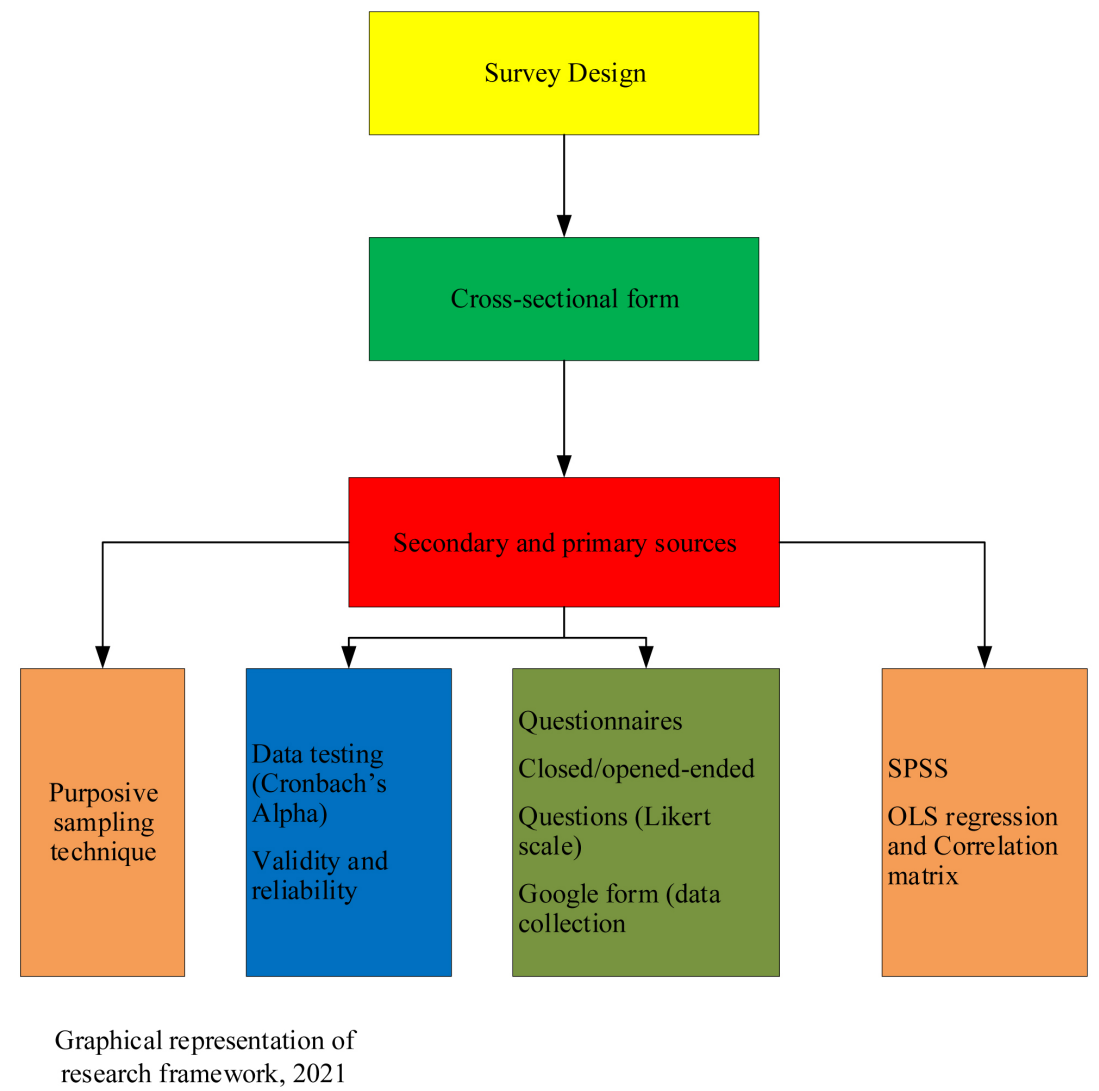

Figure 2. Shows the technical framework. 
research was preferred over other methods due to its several advantages. It will provide fast, efficient, and precise ways and means of arriving at information regarding the target population of the study. It is much desired and suitable where secondary data is deficient. Having realized that secondary data on creative thinking and innovative ability in the entrepreneurship sector in the Eastern Region may not available. Hence, using this research approach by surveying to gain much information that will be necessary for the study (Barnett-Page and Thomas, 2009). This approach is meant to elicit the opinions and perceptions of entrepreneurs and managers.

\subsection{Instrument for Data Collection}

The data for this work comprises both primary and secondary data, while the primary data will be used to a greater extent. Data on creative thinking and innovative ability of entrepreneurial activities, journals, articles, books, magazines, newsletters, and the internet will constitute secondary sources of data because the information already exists before the conduct of this research work. But more importantly, to produce the necessary data on this research the primary data will be much preferred. We administered questionnaires as survey instruments in a form of a closed-ended set before the study using the Likert scale.

\subsection{Population and Sampling Procedures}

A target population of 800 enterprises was considered for the study. However, out of the estimated sample size of 267 enterprises, 257 valid responses were used in the data analysis were gotten from Nnewi South and North in Nigeria. These sampled enterprises were selected based on their nature of activities in Nnewi. This approach was much preferred and employed due to difficulty in gathering data to establish a fact or make a generalization on creativity and innovation, and entrepreneurship development in Nigeria. The following enterprises constituted the sample frame for the research. Considering the research strategy, entrepreneurs namely manufacturers, tailors and dressmakers, hairdressers/beauticians, Shoe-makers, catering services, and carpenters were contacted for the study.

\subsection{Sample of the Study}

A fraction of the population was studied. A sample is a subset of a population that is analyzed to conclude the entire population. As a result, sampling can be described as the process of selecting a subset of a population or universe to represent the entire population or universe. The ultimate aim of sampling is to reflect the population that the study is intended to serve (De Vaus, 2002). As a result, sampling saves resources, labor, and time while allowing for a higher overall degree of accuracy. The purposive sampling technique under the Simple random sampling method was much more desired for this research to derive an appropriate sample size of 257 out of the estimated sample population of 800. In 
clear terms, the purposive sampling technique depicted the population to be studied that has much information on creativity and innovation and entrepreneurship development. This permitted an accuracy of information desired for the research. According to Taherdoost (2016), have also postulated that sampling ensures the proper representation of the stratification variables. In other words, enhances the representation of other variables.

According to Yemane (1967) as cited in Glenn D. Israel (1992), mathematical formulae will be the best preferred for determining a representative or estimated sample of 267, out of which 257 were valid. The formulae provide a standardized margin of error and confidence levels per a given population as a guide to justify the desired sample required for a valid examination of a social phenomenon.

Determining sample size for this study was arrived at by employing the mathematical formulae as follows;

$$
n=\frac{N}{1+N(\alpha)^{2}}
$$

where:

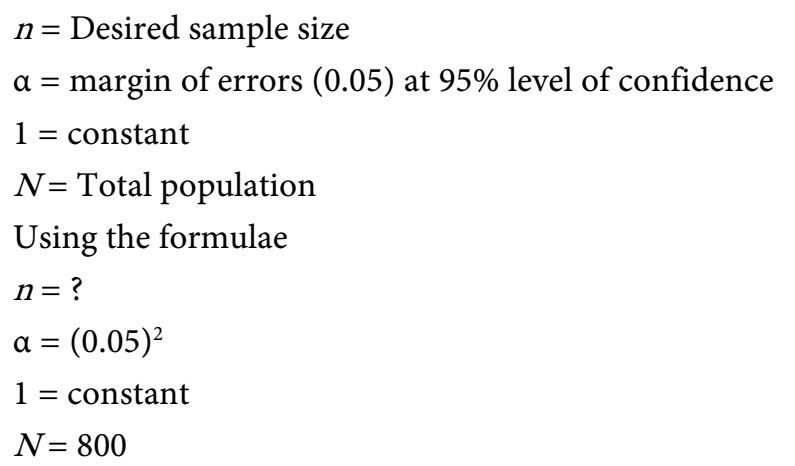

$$
n \geq \frac{800}{1+800(0.05)^{2}}=267
$$

\subsection{Data Presentation and Analysis}

In certain cases, analysis employs a variety of approaches to interpret data obtained through various methods. Self-administered questionnaires were used to collect quantitative data, and answers were coded and entered into SPSS for analysis. However, numeric values were not assigned to all qualitative results. Coding is important because it aids information retrieval (Onwuegbuzie et al., 2012).

\subsection{Analysis Method: Using SPSS (OLS Regression Analysis Methods) and Correlation Matrix}

According to Landau and Everitt (2003), SPSS is the best tool for analyzing data, creating tables and graphs, and determining relationships between the variables. As a result, data were generated and analyzed using SPSS version 25.0. To get nice and colorful charts for data presentation, we then backed it up with Micro- 
soft Excel. In this research, the descriptive statistics method for presenting and summarizing bio-data was adopted. But more importantly, a statistical or numerical instrument that was used in this research analysis was primarily inferential statistics, precisely OLS regression analysis, and correlation matrix. This statistical method aided the researchers to comprehend and appreciate large quantities of data and effectively communicate their significance in the research. Descriptive modules were used to analyze the data. This method permitted us to group the data and organize them into thematic areas and patterns for easy interpretation as espoused by (Saunders et al., 2019). The main goal was to identify the current state of creativity and innovation in Nigeria, as well as the development of entrepreneurship. The results about creativity and innovation effects on business enterprises and recommendations for business growth and sustenance in the Eastern region of Nigeria have been presented in the form of narratives.

\section{Modelling, Methodological Framework, and Data}

This paper scrutinizes the causal relationship between creativity and innovation on entrepreneurship development in Nigeria. The analysis in this paper followed an established pattern in using the Ordinary Least Squares (OLS) model after estimating the descriptive statistics covering six (6) variables. The general form of our empirical multiple regression model can be specified as;

$$
\mathrm{ED}=\alpha_{0}+\beta_{1} \mathrm{GPS}+\beta_{2} \mathrm{CI}+\beta_{3} \mathrm{TA}+\beta_{4} \mathrm{R}+\beta_{5} \mathrm{~S}+\varepsilon
$$

where;

$$
\begin{aligned}
& \text { GPS = Government policy support } \\
& \alpha=\text { Constant } \\
& \beta=\text { Change in variable } \\
& \text { CI = Creativity and Innovation } \\
& \text { TA = Technological Advancement } \\
& R=\text { Resources } \\
& S=\text { Strategies } \\
& \text { ED = Entrepreneurship Development } \\
& \varepsilon=\text { error of term }
\end{aligned}
$$

\subsection{Empirical Results and Discussions}

In our survey, we used descriptive statistics to analyze the responses, and the results are shown in Table 1 . The majority of our respondents, 62 percent, were males, while 38 percent were females, according to the findings. Results also indicated that $39 \%$ of our respondents were between the ages of $41-50,28 \%$ between the ages of $51-60,15.5 \%$ between the ages of $20-30,13.6 \%$ between the ages of $31-40$, and $3 \%$ are $60+$ years respectively. Most of these respondents had secondary education which accounted for $37.7 \%$, followed by tertiary education accounting for $32.6 \%$, basic education accounting for $18.3 \%$, and $11.3 \%$ representing respondents with no educational background. It also observed that 
Table 1. Descriptive statistics of respondents.

\begin{tabular}{|c|c|c|c|}
\hline \multicolumn{2}{|c|}{ Variables } & \multirow{2}{*}{$\begin{array}{c}\text { Frequency } \\
101\end{array}$} & \multirow{2}{*}{$\begin{array}{c}\text { Percent } \\
39\end{array}$} \\
\hline & Nnewi South & & \\
\hline 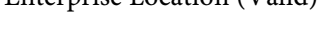 & Nnewi North & 156 & 61 \\
\hline \multirow{2}{*}{ Gender (Valid) } & Female & 97 & 38 \\
\hline & Male & 160 & 62 \\
\hline \multirow{5}{*}{ Age (Valid) } & $20-30$ & 40 & 16 \\
\hline & $31-40$ & 35 & 14 \\
\hline & $41-50$ & 101 & 39 \\
\hline & $51-60$ & 73 & 28 \\
\hline & $60+$ & 8 & 3 \\
\hline \multirow{4}{*}{ Marital Status Valid } & Single & 42 & 16 \\
\hline & Married & 167 & 65 \\
\hline & Divorced & 31 & 12 \\
\hline & Widowed & 17 & 7 \\
\hline \multirow{4}{*}{ Educational Level Valid } & None & 29 & 11 \\
\hline & Basic Education & 47 & 18 \\
\hline & Secondary Education & 97 & 38 \\
\hline & Tertiary & 84 & 33 \\
\hline \multirow{7}{*}{ Type of businesses Valid } & Manufacturing & 95 & 37 \\
\hline & Tailors \& Dressmakers & 69 & 27 \\
\hline & Shoe-making & 20 & 8 \\
\hline & Hairstyling & 21 & 8 \\
\hline & Carpentry & 20 & 8 \\
\hline & Catering Services & 32 & 12 \\
\hline & Total & 257 & 100 \\
\hline
\end{tabular}

Field survey, (2021).

the majority of the respondents were married accounting for $64.9 \%, 16.3 \%$ being single, $12.1 \%$ and $6.6 \%$ were divorced and widowed respectively. With business type, $36.9 \%$ of the respondent accounted for Manufacturing whilst the remaining $26.8 \%$ accounted for the Tailors \& Dressmakers. $12.5 \%$ accounted for Catering Services, $8.2 \%$ being Hairstyling, whereas $7.8 \%$ represent both Shoe-making and Carpentry works.

Table 2 shows the statistical description of the variables, the results show that the variables are not wider apart from themselves. The same samples were arrived at. Looking at the minimum values, maximum values, mean values, and standard deviations are almost closer in terms of values. This means that the variable is not wider dispersed from the mean. The variables generally show low standard deviation values. 
Table 2. Statistical description of all variables applied in the data analysis.

\begin{tabular}{cccccc}
\hline & N & Minimum & Maximum & Mean & Std. Deviation \\
\hline GPS & 257 & 1 & 5 & 3.282 & 0.969 \\
CI & 257 & 1 & 4 & 2.957 & 0.611 \\
TA & 257 & 1 & 5 & 3.652 & 0.743 \\
R & 257 & 1 & 5 & 3.646 & 0.904 \\
S & 257 & 1 & 5 & 3.642 & 0.851 \\
ED & 257 & 1 & 5 & 3.644 & 0.856 \\
Valid N (listwise) & 257 & & & &
\end{tabular}

Field survey, (2021).

Table 3 indicates the degree to which the study's findings can be replicated using similar methods is regarded as accurate (Healy and Perry, 2000). Reliability also refers to consistency. A scale or test is said to be accurate if repeated measurements taken under the same conditions yield the same result (Healy and Perry, 2000). Cronbach's Alpha is a reliability coefficient that determines how good items in a set are related positively. The reliability of multi-question Likert scale surveys is determined using Cronbach's alpha tests. It rates the inter-correlations between test items, with a score of 1 indicating higher internal quality and reliability and a score of 0.7 to 0.9 indicating acceptable results (Landau and Everitt, 2003). The calculated Cronbach's alpha value for all scales of measurement variables is 0.759 in Table 2, suggesting a correlation between the items and the questions; as a result, the questionnaire used in our research is reliably accurate.

Validity decides whether the study tests what it was designed to test, as well as the accuracy of the research findings. According to Golafshani (2003), research validity is "construct validity." The construct is the initial concept question or hypothesis that decides which data should be collected and how it should be collected. My supervisor thoroughly checked the questionnaires for adequacy and representativeness to ensure that they covered all of the variables being tested. A pilot test was conducted using thirty-five (35) respondents from the entrepreneurial sector to determine the accuracy and validity of the instruments. This helped the researcher to modify the research instrument making it clear to understand and eliminate the uncertainty of items before the final distribution.

Table 4 shows the correlation matrix, where government policies negatively correlated with creativity and innovation at a $10 \%$ significant level $\left(0.364^{\star *}\right)$. Therefore, the alternative hypothesis (H1) is rejected. Since GPS correlated negatively with $\mathrm{CI}$, hence not favorable for entrepreneurship development and economic growth. The matrix shows that most of the measured items correlated at a $1 \%$ significant level. In all, CI correlated strongly with TA at a $1 \%$ significant level $\left(0.499^{* *}\right)$. This indicates that creativity and innovation, and technology 
Table 3. Reliability test and case processing summary.

\begin{tabular}{ccc}
\hline & N & $\%$ \\
\hline Cases Valid & 252 & 98 \\
Excluded & 5 & 2 \\
Total & 257 & 100 \\
Cronbach's Alpha & 0.759 & 26
\end{tabular}

Table 4. Pearson's correlation coefficient: matrix.

\begin{tabular}{|c|c|c|c|c|c|c|}
\hline Variables & GPS & $\mathrm{CI}$ & TA & $\mathrm{R}$ & S & ED \\
\hline \multirow{3}{*}{$\begin{array}{c}\text { GPS } \\
\text { Sig. (2-Tailed) } \\
\mathrm{N}\end{array}$} & 1 & 0.057 & $0.195^{\star *}$ & $0.171^{\star *}$ & 0.074 & 0.084 \\
\hline & & 0.364 & 0.002 & 0.006 & 0.235 & 0.180 \\
\hline & 257 & 257 & 257 & 257 & 257 & 257 \\
\hline \multirow{3}{*}{$\begin{array}{c}\text { CI } \\
\text { Sig. (2-Tailed) } \\
\text { N }\end{array}$} & 0.057 & 1 & $0.499^{\star *}$ & $0.300^{\star \star}$ & $0.260^{\star \star}$ & $0.155^{\star}$ \\
\hline & 0.364 & & 0.000 & 0.000 & 0.000 & 0.013 \\
\hline & 257 & 257 & 257 & 257 & 257 & 257 \\
\hline \multirow{3}{*}{$\begin{array}{c}\text { TA } \\
\text { Sig. (2-Tailed) } \\
\mathrm{N}\end{array}$} & $0.195^{\star *}$ & $0.499^{\star *}$ & 1 & $0.431^{\star *}$ & $0.446^{\star *}$ & $0.293^{* *}$ \\
\hline & 0.002 & 0.000 & & 0.000 & 0.000 & 0.000 \\
\hline & 257 & 257 & 257 & 257 & 257 & 257 \\
\hline \multirow{3}{*}{$\begin{array}{c}\mathrm{R} \\
\text { Sig. (2-Tailed) } \\
\mathrm{N}\end{array}$} & $0.171^{* *}$ & $0.300^{\star *}$ & $0.431^{\star *}$ & 1 & $0.253^{\star \star}$ & 0.081 \\
\hline & 0.006 & 0.000 & 0.000 & & 0.000 & 0.194 \\
\hline & 257 & 257 & 257 & 257 & 257 & 257 \\
\hline \multirow{3}{*}{$\begin{array}{c}\text { S } \\
\text { Sig. (2-Tailed) } \\
\mathrm{N}\end{array}$} & 0.074 & $0.260^{\star *}$ & $0.446^{\star *}$ & $0.253^{\star *}$ & 1 & $0.260^{* *}$ \\
\hline & 0.235 & 0.000 & 0.000 & 0.000 & & 0.000 \\
\hline & 257 & 257 & 257 & 257 & 257 & 257 \\
\hline \multirow{3}{*}{$\begin{array}{c}\text { ED } \\
\text { Sig. (2-Tailed) } \\
\mathrm{N}\end{array}$} & 0.084 & $0.155^{*}$ & $0.293^{\star *}$ & 0.081 & $0.260^{\star *}$ & 1 \\
\hline & 0.180 & 0.013 & 0.000 & 0.194 & 0.000 & \\
\hline & 257 & 257 & 257 & 257 & 257 & 257 \\
\hline
\end{tabular}

**. Correlation is significant at the 0.01 level (2-tailed).

advancement are important elements in entrepreneurship development (Acs and Audretsch, 2005; Ballor and Claar, 2019). These two variables play a major role in the success of a country's entrepreneurial development. Therefore, being creative and innovative requires creative thinking and innovative ability of individuals, and technological advancement to propel economic growth. However, entrepreneurship development, resources, and strategy correlated with technology advancement $\left(0.431^{* *}, 0.446^{* *}, 0.293^{* *}\right)$ at a $1 \%$ significant level. This is an indication there is a significant and positive relationship between the construct variables. Therefore, can be considered as propelling factors of entrepreneurship development. 


\subsection{Regression Analysis}

Table 5 indicates that the R-value of 0.334 shows a good level of prediction. The $\mathrm{R}$ square value of 0.112 shows that our independent variable explains the $11 \%$ variability of our dependent variable (entrepreneurship development). Hence, $89 \%(100 \%-11 \%)$ variation is caused by factors other than predictors included in this model. The adjusted R square value of 0.094 indicates $9 \%$ of the variation in the outcome variable which is explained by the independent variables.

We have compared the variables in Table 6 , in terms of measurement of variance for two or more factors. We used the ANOVA test to determine the influence that independent variables have on the dependent variable in a regression study. The overall regression model was checked for a good fit for the data using the F-ratio in the ANOVA (Table 4). The series of residual point values of variance is 251 , while the series of residual point number of squares value is 187.67 , according to the table. This demonstrates that the independent variable has a statistically important relationship with the dependent variables, $\mathrm{F}(5,251)$ $=6.315, p(0.000)<0.05$ (the regression model is a good fit for the data). Hence, the ability to influence the dependent variable. Therefore, the test conditions determine the favorability or un-favorability for predicting the market outcome, the person (the entrepreneur) will assume the risk of making a profit or losing money due to unexpected and uncontrollable circumstances (Babu et al. 2013).

Table 5: Standardized Coefficients values (OLS Regression) and Hypotheses

H1: Government policy support on entrepreneurship development (Not significant)

H2: Technological advancement influences entrepreneurship development (Significant)

H3: Creativity and innovation are means to entrepreneurship development (Not Significant).

H4: Available resources influence entrepreneurship development (Not significant).

H5: Strategy influences entrepreneurship development (Significant).

Table 5. Model summary.

\begin{tabular}{cccc}
\hline $\mathrm{R}$ & $\mathrm{R}$ Square & Adjusted R Square & Std. Error of the Estimate \\
\hline $0.334 \mathrm{a}$ & 0.112 & 0.094 & 0.815 \\
\hline
\end{tabular}

a. Predictors: (Constant), S, GPS, CI, R, TA.

Table 6. ANOVA test.

\begin{tabular}{cccccc}
\hline & Sum of Squares & df & Mean Square & F & Sig. \\
\hline Regression & 20.97 & 5 & 4.194 & 6.315 & $0.000^{*}$ \\
Residual & 166.70 & 251 & 0.664 & & \\
Total & 187.67 & 256 & & & \\
\hline
\end{tabular}

Dependent Variable: ED; ${ }^{*}$ Predictors: (Constant), S, GPS, CI, R, TA. 
Table 7 illustrates the statistical estimation of the explanatory variables on the dependent variable. The test values indicate that TA and $\mathrm{S}$ have a positive significance on ED at a $5 \%$ level; $p(0.003)<0.05$, whereas $\mathrm{S}$ is at a $10 \%$ significant level although positive; $p(0.013)<0.05$. The test variables for GPS, CI and $\mathrm{R}$ are not statistically with $p(0.544)<0.05, p(0.840)<0.05$, and $p(0.274)<0.05$, all at $10 \%$ significant levels respectively. However, the t-test for resources correlated negatively with entrepreneurship development. This is an indication that resource (explanatory variable) is impacting negatively on the dependent variable (entrepreneurship development). Hence, serving as an impediment to entrepreneurship development. The result is an indication that entrepreneurs must consider crucial factors that will either propel or impede entrepreneurship development in their business start-ups, and the potential to revolutionize production patterns by leveraging an innovation (Antonites and Van Vuuren, 2014).

Table 8 shows the standard residual value $(-2.890)$ of the predicted variables on the dependent variable shows that the data set is normally distributed. Since the standard residual value does not exceeds -2 to 2 when plotted. However, the

Table 7. A Robust estimation of the variables using the OLS Regression method.

\begin{tabular}{cccccc}
\hline Explanatory variables & \multicolumn{2}{c}{$\begin{array}{c}\text { Unstandardized } \\
\text { Coefficients }(\beta)\end{array}$} & $\begin{array}{c}\text { Standardized } \\
\text { Coefficients }(\beta)\end{array}$ & $t$ & Sig. \\
\hline Constant & 2.128 & 0.348 & & 6.123 & 0.000 \\
GPS & 0.033 & 0.054 & $0.037^{*}$ & 0.608 & $0.544^{*}$ \\
CI & 0.020 & 0.097 & $0.014^{*}$ & 0.202 & $0.840^{*}$ \\
TA & 0.272 & 0.090 & $0.236^{*}$ & 3.005 & $0.003^{*}$ \\
R & -0.069 & 0.063 & $-0.073^{*}$ & -1.096 & $0.274^{*}$ \\
S & 0.168 & 0.067 & $0.167^{*}$ & 2.503 & $0.013^{*}$ \\
\hline
\end{tabular}

Dependent Variable: ED.

Table 8. Residuals statistics.

\begin{tabular}{ccccc}
\hline & Minimum & Maximum & Mean & Std. Deviation \\
\hline Predicted Value & 2.58 & 4.63 & 3.79 & 0.364 \\
Std. Predicted Value & -3.324 & 2.306 & 0.000 & 1.000 \\
Standard Error of Predicted Value & 0.105 & 0.367 & 0.224 & 0.048 \\
Adjusted Predicted Value & 2.50 & 4.61 & 3.79 & 0.372 \\
Residual & -2.939 & 2.316 & 0.000 & 0.993 \\
Std. Residual & -2.890 & $2.277^{*}$ & 0.000 & 0.976 \\
Stud. Residual & -2.971 & 2.365 & 0.001 & 1.005 \\
Deleted Residual & -3.119 & 2.499 & 0.001 & 1.052 \\
Stud. Deleted Residual & -3.021 & 2.388 & 0.000 & 1.009 \\
Mahal. Distance & 1.695 & 32.005 & 11.953 & 5.469 \\
Cook's Distance & 0.000 & $0.061^{*}$ & 0.005 & 0.007 \\
Centred Leverage Value & 0.007 & 0.126 & 0.047 & 0.022 \\
\hline
\end{tabular}

Dependent Variable: ED. 
cook's distance $(0.061)$ of all predictor variables, in this case, indicates an influential value on the dependent variable. Having analyzed this, below is a graphical representation of the residual statistics.

\section{Conclusion}

The issue of creativity and innovation, and entrepreneurship development is still a critical area that needs more research, toppled with practical solutions to avert the slow growth of the sector (Onuselogu \& Zita, 2018). However, Schumpeterian views on creativity as a criterion of entrepreneurship, with one of its distinguishing characteristics being the ability to do new things that have not been done before, cannot be realized without considering the technological advancement and strategies to bring innovation or new things into existence. It is therefore imperative to adequately assess some variables that are haves positive and negative effects on entrepreneurship development. To check the robustness of our findings we used OLS as the baseline regression, and other advanced methods such as ANOVA Test to enhance the credibility of our results. Our test values of coefficients indicate that technological advancement and strategy have a positive impact on entrepreneurship development. The test results indicate that technological advancement and strategy are necessary and influential factors to be considered in the quest of developing the entrepreneurial sector.

Again, most of the variables tested are statistically not significant. This result shows that the impact of government policy support, creative thinking, and innovative ability of entrepreneurs as well as the availability of resources are impacting insignificantly on entrepreneurship development. This can be considered as empirical reasons for failed enterprises not only in Nigeria.

Interestingly, the correlation matrix performed showed that creativity and innovation correlated strongly with technological advancement. This indicates that technological advancement is support for creativity and innovation. However, its direct effect on entrepreneurship development was not significantly estimated. This can further be investigated to ascertain reality. The results further indicate that there is a strong relationship between creativity and innovation, and technology (Acs and Audretsch, 2005; Ballor and Claar, 2019). We, therefore, established that to develop the entrepreneurial sector requires been creative and innovative, largely depends on the mapping strategy and technological advancement in other to achieve economic success. Further estimations of our variables such as Government policy support, creativity and innovation, and resources were insignificantly impacted on the dependent variable (entrepreneurship development). The most significant variables in this research are technological advancement and strategy.

The most influential variables in this research are quite different (Ali Al Qudah, 2018). The two measured significant variables can then be considered as major factors for innovation and the success of a country's entrepreneurial development. Having established this fact is a call on policy support and frame- 
work-specific not only for Nigeria but to any other country which is striving to achieve economic success. An additional test can be performed to either prove or disprove. We are therefore in the position that current research and report on creativity and innovation for entrepreneurship development modeling and potential have not been fully investigated and exploited. We then propose the following as reference points.

\subsection{Recommendation for Further Research}

We encourage the entrepreneurial and the business sector to embrace the original Schumpeterian concept of innovation, which referred to fundamental uniqueness in all of its forms and to widen away from its focus on high-tech industrial sectors. Although, the concept of entrepreneurship, creativity, and innovation set the tone for the creation of new things, technology, and strategy to facilitate entrepreneurship development and economic growth is key in this regard. However, economic success cannot be achieved without combining other elements such as Government/management support, resources, and culture. These are pertinent to economic growth. Therefore, the findings of this research have established a strong relationship between technological advancement, and strategy on entrepreneurship development. Hence, a call on policy support and framework not only for Nigeria but to any other country which is striving for economic success.

On the contrary, future research can be done to estimate and test other explanatory variables which were not significant and those which were not included in the variables tested such as culture to establish its impact on entrepreneurship development. Since not all estimated variables were statistically significant. Therefore, the entrepreneurship sector is an area that needs more attention in terms of contributions to research and its replica effect on economic growth and prosperity.

\subsection{The Difficulties of the Paper}

The researcher encountered the following as research limitations:

Some respondents not answering the questions. We were constraint with time and financial resources to meet the transportation cost of data collection. But notwithstanding, we tried to gather relevant information through personal contact and questionnaire administration in Google form which respondents answered to the best of their knowledge.

\subsection{Innovation of the Paper}

Reflecting on Schumpeter's perspectives regarding innovation and entrepreneurship theory, it is, therefore, prudent to factor this thinking/knowledge in quest of pursuing economic agenda to propel entrepreneurs to be creative and innovative in their economic activity. However, this can happen effectively by considering the necessary factors such as resources, technology, strategy, culture, 
and government/management support. The outcome of this intervention will engineer new inventions, problem-solving, risk reduction, competitive advantage, empowerment, and building the capacity of most businesses. This will ease business failures and enhance entrepreneurship development across the globe. Hence, adoption of the theory and practice.

The study aims at establishing an argument and support for the policy in the entrepreneurial sector to enable sustenance and ease the failure of most enterprises due to the inability of entrepreneurs to inject innovative practices into their businesses to reduce the collapse of businesses in Nigeria. This will eventually help the country reap its economic benefit. Therefore, this is an area of research interest for policy formation by focusing on its impact on entrepreneurship development.

\section{Conflicts of Interest}

As authors of this paper, we declare no conflict of interest regarding the publication.

\section{References}

Acs, Z. J., \& Audretsch, D. B. (2005). Entrepreneurship, Innovation, and Technological Change. Foundations and Trends ${ }^{\circledR}$ in Entrepreneurship, 1, 149-195.

https://doi.org/10.1561/0300000004

Ali Al Qudah, M. (2018). The Impact of Entrepreneurship Initiatives in Enhancing Creativity and Innovation. International Journal of Business and Management, 13, 157-168. https://doi.org/10.5539/ijbm.v13n7p157

Amabile, T. M. (1988). A Model of Creativity and Innovation in Organizations. Research in Organizational Behavior, 10, 123-167.

Antonites, A. J., \& Van Vuuren, J. J. (2014). Inducing Entrepreneurial Creativity, Innovation and Opportunity-Finding Skills. South African Journal of Economic and Management Sciences, 8, Article No. a1197. https://doi.org/10.4102/sajems.v8i3.1197

Aydin, E. (2015). Creativity and Innovation in Entrepreneurship. London: Brunel University.

Babu, R. R., Krishna, M. M., \& Swathi, A. (2013). Role of Creativity and Innovation in Entrepreneurship. Innovative Journal of Business and Management, 2, 112-115.

Ballor, J. J., \& Claar, V. V. (2019). Creativity, Innovation, and the Historicity of Entrepreneurship. Journal of Entrepreneurship and Public Policy, 8, 513-522. https://doi.org/10.1108/JEPP-03-2019-0016

Barnard, B., \& Herbst, D. (2018). Entrepreneurship, Innovation and Creativity: The Creative Process of Entrepreneurs and Innovators. Expert Journal of Business and Management, 7, 107-146. https://doi.org/10.2139/ssrn.3195912

Barnett-Page, E., \& Thomas, J. (2009). Methods for the Synthesis of Qualitative Research: A Critical Review. BMC Medical Research Methodology, 9, Article No, 59. https://doi.org/10.1186/1471-2288-9-59

Barroso-Tanoira, F. G. (2017). Motivation for Increasing Creativity, Innovation and Entrepreneurship. An Experience from the Classroom to Business Firms. Journal of Innovation Management, 5, 55-74. https://doi.org/10.24840/2183-0606 005.0030005 
Baykal, E. (2018). Innovativeness in Family Firms: Effects of Positive Leadership Styles. In H. Dincer, Ü. Hacioglu, \& S. Yüksel (Eds.), Strategic Design and Innovative Thinking in Business Operations (pp. 213-232). Cham: Springer. https://doi.org/10.1007/978-3-319-77622-4_11

Becker, M. C., Knudsen, T., \& Swedberg, R. (2012). Schumpeter's Theory of Economic Development: 100 Years of Development. Journal of Evolutionary Economics, 22, 917933. https://doi.org/10.1007/978-3-319-77622-4_11

Bélanger, S., Veilleux, S., \& Tremblay, M. (2016). A Conceptual Framework on the Role of Creativity in Sustaining Continuous Innovation in New Product Development. International Journal of Product Development, 21, 190-211. https://doi.org/10.1504/IJPD.2016.078866

Box, S. (2009). OECD Work on Innovation-A Stocktaking of Existing Work. Organisation für wirtschaftliche Zusammenarbeit und Entwicklung (OECD).

Byers, V. (2017). Creativity, Innovation and Change (pp. 177-191).

Clow, J. E. (2008). Entrepreneurship Teaching Strategies Roston. National Business Education Association, 1, 102-112.

De Vaus, D. (2002). Analyzing Social Science Data: 50 Key Problems in Data Analysis. Thousand Oaks, CA: SAGE Publications Ltd.

Edralin, D. M., Tibon, M. V. P., Poblador, P. E. T., \& Yu, J. W. (2019). Creativity, Innovation, and Sustainability: Insights of Entrepinays in the Handicrafts Industry. DLSU Business \& Economics, 28, 64-79. https://doi.org/10.4018/jec.2008100101

Fedorowicz, J., Laso-Ballesteros, I., \&Padilla-Meléndez, A. (2008). Creativity, Innovation, and E-Collaboration. International Journal of E-Collaboration, 4, 1-10.

Fields, Z. (2016). Using Creativity and Social Innovation to Create Social Value and Change. In Z. Fields (Ed.), Incorporating Business Models and Strategies into Social Entrepreneurship (pp. 97-112). Hershey, PA: IGI Global. https://doi.org/10.4018/978-1-4666-8748-6.ch006

Fillis, D. I. (2010). The Art of the Entrepreneurial Marketer. Journal of Research in Marketing and Entrepreneurship, 12, 87-107. https://doi.org/10.1108/14715201011090576

Fillis, I., \& Rentschler, R. (2010). The Role of Creativity in Entrepreneurship. Journal of Enterprising Culture, 18, 49-81. https://doi.org/10.1142/S0218495810000501

Finkle, T. A. (2013). Creativity, Innovation and Entrepreneurship: The Case of H. Wayne Huizenga. Journal of the International Academy for Case Studies, 19, 71-85.

Gholami, K., \& Karimi, A. (2014). The Role of Creativity, Innovation and Entrepreneurship in the Organization. Bulletin of Environment, Pharmacology and Life Sciences Journal, 3, 73-77. http://www.bepls.com

Golafshani, N. (2003). Understanding Reliability and Validity in Qualitative Research. The Qualitative Report, 8, 597-607.

Gontur, S., Davireng, M., \& Gadi, P. D. (2016). Creativity and Innovation as a Strategy for Enhancing Entrepreneurship Development in Nigeria. Journal of Teacher Perspective, 10, 1-16.

Healy, M., \& Perry, C. (2000). Comprehensive Criteria to Judge Validity and Reliability of Qualitative Research within the Realism Paradigm. Qualitative Market Research, 3, 118126. https://doi.org/10.1108/13522750010333861

Ibbotson, P. (2008). Creativity, Innovation and Leadership. In The Illusion of Leadership (pp. 74-84). London: Macmillan. https://doi.org/10.1057/9780230202009 9

Jain, T. K. (2019). Creativity, Innovation and Entrepreneurship: Agenda for India. SSRN 
Electronic Journal. https://doi.org/10.2139/ssrn.3318064

Klein, P. G. (2008). Opportunity Discovery, Entrepreneurial Action, and Economic Organization. Strategic Entrepreneurship Journal, 2, 175-190. https://doi.org/10.1002/sej.50

Korsgaard, S. and Anderson, A. (2011). Enacting Entrepreneurship as Social Value Creation. International Small Business Journal: Researching Entrepreneurship, 29, 135-151. https://doi.org/10.1177/0266242610391936

Landau, S., \& Everitt, B. S. (2003). A Handbook of Statistical Analyses Using SPSS. New York: Chapman and Hall/CRC. https://doi.org/10.1201/9780203009765

Neely, A., \& Hii, J. (1998). Innovation and Business Performance: A Literature Review. Cambridge: University of Cambridge.

Nnadi, C. (2014a). The Role of Creativity and Innovation in Business Growth and Sustainability: An Ideal Model. International Journal of Economics and Management Sciences, 3, Article No, 171. https://doi.org/10.4172/2162-6359.1000171

Nnadi, C. (2014b). Entrepreneurship Development and Its Impact on Small Scale Business Enterprises in Developing Countries: A Nigerian experience. Journal of Entrepreneurship \& Organization Management, 3, Article No. 119. https://doi.org/10.4172/2169-026X.1000119

NPC, J. P. (2006). Population and Housing Census of the Federal Republic of Nigeria.

Oke, A., Munshi, N., \& Walumbwa, F. (2009). The Influence of Leadership on Innovation Processes and Activities. Organizational Dynamics, 38, 64-72. https://doi.org/10.1016/j.orgdyn.2008.10.005

Okpara, D. F. O. (2007). The Value of Creativity and Innovation in Entrepreneurship. Journal of Asia Entrepreneurship and Sustainability, 3, 1-13.

Onugu, B. A. N. (2005). Small and Medium Entreprises (SMEs) in Nigeria: Problems and Prospects. Small Business Journal.

Onuselogu, A., \& Zita, C. O. (2018). Creative Innovations in Tertiary Institutions: A Tool for Sustainable Development of Nigerian Economy. COOU Journal of Educational Research, 4.

Onwuegbuzie, A. J., Leech, N. L., \& Collins, K.M. (2012). Qualitative Analysis Techniques for the Review of the Literature. Qualitative Report, 17, 1-28.

Phan, P., Zhou, J., \& Abrahamson, E. (2015). Management and Organization Review Special Issue on 'Creativity, Innovation and Entrepreneurship in China'. Management and Organization Review, 4, 151-152. https://doi.org/10.1017/S1740877600000553

Roopsing, T., \& Nokphromph, N. (2017). Factors Affecting Creative Innovation for Entrepreneur in the Furniture Industry Business in Asia. Asian Journal of Marketing, 12, 12-20. https://doi.org/10.3923/ajm.2018.12.20

Sart, G. (2013). Effects of Technology Transfer Offices on Capacity Building in Creativity, Innovation and Entrepreneurship. The European Journal of Social \& Behavioural Sciences, 4, 704-712. https://doi.org/10.15405/FutureAcademy/ejsbs(2301-2218).2012.4.5

Saunders, M. N., Lewis, P., Thornhill, A., \& Bristow, A. (2019). Understanding Research Philosophy and Approaches to Theory Development. In M. N. K. Saunders, P. Lewis, \& A. Thornhill (Eds.), Research Methods for Business Students (pp. 128-171). Harlow: Pearson.

Schumpeter, J. A. (1934). The Theory of Economic Development. Cambridge: Harvard University Press.

Taherdoost, H. (2016). Sampling Methods in Research Methodology: How to Choose a 
Sampling Technique for Research. SSRN Electronic Journal, 5, 18-27.

https://doi.org/10.2139/ssrn.3205035

Vétillart, G. (2014). Creativity \& Leadership: The Introduction of Creative Internal Communication Practices in Organizations. Sweden: Linnaeus University.

WBG (World Bank Group) (2020). Region Profile of Sub-Saharan Africa. Doing Business 2020 Indicators. Washington DC: World Bank Group.

Weigel, F. K., Hazen, B. T., Cegielski, C. G., \& Hall, D. J. (2014). Diffusion of Innovations and the Theory of Planned Behavior in Information Systems Research: A Meta-Analysis. Communications of the Association for Information Systems, 34, 619-636. https://doi.org/10.17705/1CAIS.03431

Yamane, T. (1967). Statistics, an Introductory Analysis (2nd ed.). New York: Harper and Row. 